\title{
Silent And Incidental Presentation of Cholecystogastric Fistula
}

\author{
DattaprasadSamant*, Deepak Kumar\#, Pratik Savant^,F. P. Noronha \\ *Lecturer, \#Senior Resident, ^Junior Resident,' $\sim$ Professor, Department of Surgery, Goa Medical College.
}

\begin{abstract}
CholecystogastricFistulae are a rare variety of biliary fistulae
.Mostfistulaebetweenthegallbladderand intestinaltractbecomeobvious[1]. But here we report a rare silent presentation ofCholecystogastricfistula in a 51 year old female, whowas posted for routine laparoscopic cholecystectomy for long standing cholelithiasis.
\end{abstract}

Keyworsds: Cholecystogastric fistula, gallstones, cholelicystitis.

\section{Introduction}

Cholecystoentericfistulasconstitute70-80\%ofbiliaryfistulae.Ofthese,55-75\%arecholecystoduodenal,1530\%arecholecystocolic,and2-5\%arecholecystogastric[1]. Long standing cholelithiasis withcholecystitis may result in a number of complications like empyema gallbladder, perforation, pancreatitis and rarely bilioenteric fistulas and malignant transformation. Predisposing factors include diabetes mellitus and other immunocompromised states. Here we report a case of cholecystogastric fistula in adiabetic female with long standing cholelithiasis.

\section{Case Report}

A 51 year old female planned for laparoscopic surgery. She is a known diabetic on regular treatment and had past history of appendicectomy and caesarian section. The patient gave history of multiple episodes of abdominalpain and nausea over the past 2 years, however didn't seek medical attention.Preoperativesonography showed sludge in the region of the neck with the gall bladder outline appearing indistinctin the fundal region where a calculus of $1 \mathrm{~cm}$ was seen. The patient was explored laparoscopically which was later converted to open surgery in view dense adhesions between contracted gall bladder and stomach(fig 1).Intraoperative findings which revealed a fistula between the fundus of the gallbladder and body of the stomach near the lesser curvature with stone impactedin the Fistula(Fig 2 and 3).The patient underwent single stage open cholecystectomy with primary repair of the stomach (Fig 4). The patient had an uneventful postoperative recovery. Pathology revealed no evidence of malignancy.

\section{Discussion}

Biliary fistulae is a abnormal passage from biliary system to another location. Biliary fistulae are usually result of acute suppurative cholecystitis associated with cholelithiasis rarely it is due to peptic ulcer disease or malignancy[2]. Bilioenteric fistulas represent most common forms of biliary fistulae. Biliary fistulas occur in 3-5\% of patients with gallstones, withduodenum being the most common site of fistula. Diagnosis is difficult and requires high index of suspicion. Preoperativestudies include ultrasound, CTScan, ERCP, HIDA Scan[3]. CT being the modality of choice for diagnosis. In this case diagnosis was made during laparoscopic exploration of abdomen. The migrated stone may rarely cause gastric outlet obbsrtruction when impacted in the duodenum or intestinal obstructionmost commonly in the terminal ileum. Most commonly done surgeries include a 'one stage procedure' involving cholecystectomy, repair of the fistula and stone removal which was done in this case.Ther options include endoscopic lithotomy or lithotripsy or laparoscopic transection of cholecystoenteric fistulas using endostapler or intracorporeal suturing of the fistula depending on the facilities available and patient profile.

\section{Conclusion}

Although rare, the possibility of Cholecystogastric fistulas is worth considering in elderly diabetic females with cholelithiasis with history of recurrent cholecystitis. Surgery remains the mainstay of treatment. A special emphasis should be made on patientswith symptomatic or asymptomatic gallstines with comorbidities like diabetes and timely surgery before they develop complications. Results are often good following surgery and patients have an uneventful course. 


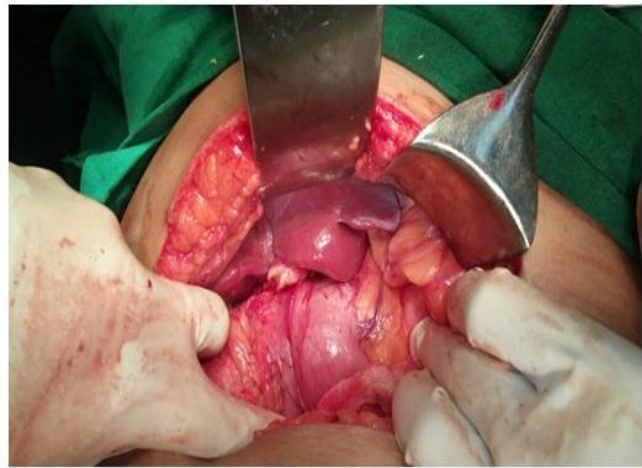

Fig 1

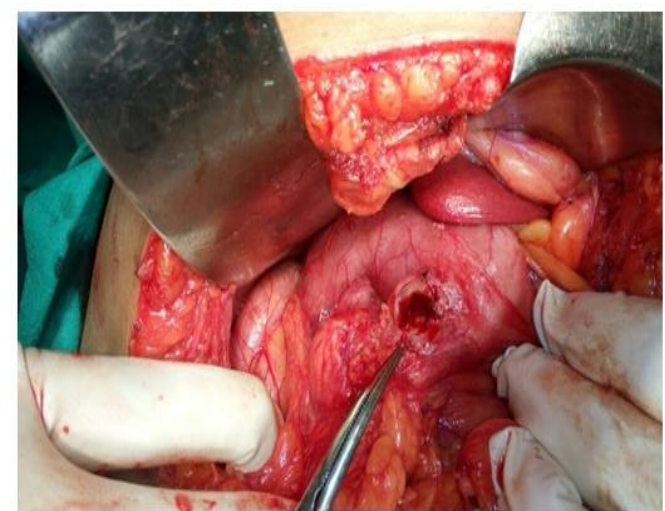

Fig 3

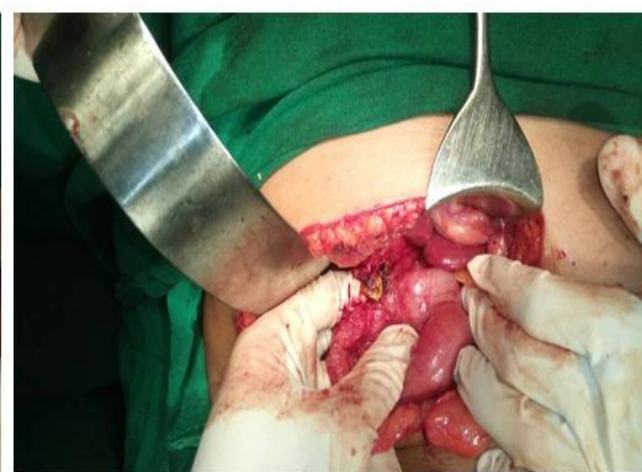

Fig2

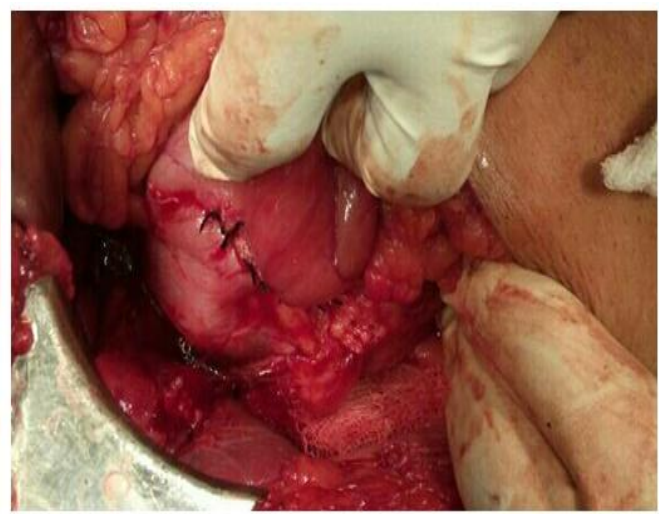

Fig 4

\section{References}

[1]. Blumgart's surgery of the liver, pancreas and biliary tract by William Jarnagin.

[2]. Pathology of pancreas, gallbladder extrahepatic biliary tree by Ernest Lack.

[3]. International journal of surgery vol 22.Cholecystocolonic fistula as a complication of cholelithiasis. A. Rodrigues-rivera, L. Ckarke

[4]. Cholecystogastricfistula: a brief report and review of the literature

[5]. Michael R. Boland,Gary A. Bass, Ian Robertson, Thomas N. Walsh

[6]. Afflerbaugh JK, Cole HA (1955) Intragastric gallstone. Radiology 64:581-583

[7]. Berliner SD, Burson LC (1965) One-stage repair for cholecystoduodenal fistula and gallstone ileus. Arch Surg 90: 313-316.

[8]. Gardner NHN, Cholecystogastricfistulae, Br Med J, 1968, vol.4

[9]. ChowbeyPK, Bandyopadhyay, SKSharmaAKhullarRSoni, VBaijalLaparoscopic management of cholecystoenteric fistulas. 